Braun: Уorläufige Mittheilung über eine neue Kobaltrerbindung. 107

\title{
XVIII.
}

\section{Vorläufige Mittheilung über eine neue Kobaltverbindung.}

\author{
Von
}

\section{Dr. C. D. Braun.}

Bei fortgesetztem Studium über das Kobalt und seine Verbindungen beobachtete ich unter Anderem eine interessante Reaction, welche bei der Einwirkung von Kaliumnitrit auf Cyankobaltkalium erzeugt wird. Bringt man nämlich zu einer Kobaltoxydullösung etwas concentrirte Cyankaliumlösung, bis der anfangs entstehende Niederschlag sich wieder zu einer gelblichen Flüssigkeit, dem Cyankobaltkalium, gelöst hat, und alsdann eine concentrirte neutrale Lösung von Kaliumnitrit, so erhält man augenblicklich eine schöne dunkelorangerothe Flüssigkeit. Statt des neutralen Kaliumnitrites lässt sich auch recht gut eine alkalische Lösung dieses Salzes verwenden, nur muss man dann den Ueberschuss des freien Kalis durch etwas Essigsäure wegnehmen. Je nach der angewandten Menge des Kobaltsalzes tritt die Reaction stärker ein. Bei Vorhandensein von etwas grösseren Quantitäten Kobalt erscheint die Flüssigkeit sogar intensiv blutroth gefärbt. Löst man etwa ein Milligramm reines Kobalt in einigen Tropfen Salpetersäure, stumpft die freie Säure darauf etwas ab, giebt dann Cyankalium und Kaliumnitrit (oder auch eine Mischung beider) in wenig Wasser gelöst hinzu, so zeigt die Flüssigkeit noch eine schöne orangerothe Farbe. Beim Schütteln bemerkt man an der Oberfläche einen schönen pfirsichblïthrothen Saum. Die Lösung der neuen Verbindung, welche muthmaasslich ein Nitrocyankobalt darstellt, besitzt ein bedeutendes Färbungsvermögen. Setzt man z. B. zu einem halben Liter Wasser in einem Becherglase, welches auf einem Blatt weissen Papiers steht, einige Tropfen von der aus ein Milligramm Kobalt erhaltenen orangerothen Lösung, so erscheint das Wasser noch deutlich orange- 
108 Braun: Vorläufige Mittheilung über eine neue Kobaltverbindung.

rosenfarben und bei Zusatz der ganzen aus ein Milligramm Kobalt erhaltenen gelösten Verbindung, nimmt das Wasser eine lierrlich orangerosenfarbene oder vielleicht besser pfirsichblüthrothe Färbung an. - Gegen Cyannickelkalium zeigt Kalinmnitrit keine sichtbare Einwirknng; es bietet diese Reaction somit auch ein Mittel, um auf einfache Weise Kobalt und Nickel mit Sicherheit von einander zu unterscheiden. Sind bei dem Kobalt jedoch erhebliche Mengen von Nickel, so tritt die Reaction nicht mehr mit Sicherheit anf. In der Hitze wird die Verbindung zersetzt, wahrscheinlich mit daher rührend, dass das Cyankobalt sich von dor salpetrigen Säure trennt und in Kobaltcyankaliun übergeht, auf welches Kalitumnitrit keine Linwirkung ausübt; doch werden erst weitere Versuche, die ich darüber anzustellen gedonke, die Sache aufhellen. Fügt man zu der orangerothen Lösung viel freie Sätre, z. B. Essigsäure, Salzsäure, so wird die Verbindung nach einiger Zeit zersetzt, man erhält eine farblose Flüssigkeit. Zersetzend wirkt ebenfalls Ammoniak, welches die Flüssigkeit nach einiger Zeit ebenfalls entfärbt, dagegen zeigt die Verbindung gegen Kali und Natron eine grössere Beständigkeit.

Da ich voraussichtlich erst im Verlaufe einiger Monate die Studien über diese neve Verbindung fortzusetzen vermag, so glaubte ich einstweilen die Existenz dieser schünen Verbindung mittheilen zu sollen,' mir dabei jedoch ausführlichere Mittheilungen darüber vorbehaltend.

Laboratoriurn von Prof. Fresenius zu Wiesbaden, Januar 1864. 